\title{
Produção de embriões in vivo e expressão dos genes IGF-IR, IGF- II, GLUT-I e HSP 70.1 em embriões de cabras alimentadas com bagaço de caju desidratado ou raspa de mandioca*
}

\section{In vivo production of embryos and genes expression of IGF-IR, IGF-II, GLUT-I and HSP 70.1 in embryos of goats fed with dried cashew bagasse or cassava root scrapings}

\author{
Iracelma Julião de Arruda, ${ }^{* *}$ Liliane Moreira Silva, ${ }^{* *}$ Cláudio Henrique de Almeida Oliveira, ${ }^{* *}$ Aline Maia Silva, ${ }^{* *}$ \\ Fabiana Vinhas Rodrigues, ${ }^{* *}$ César Carneiro Linhares Fernandes, ${ }^{* *}$ Cleidson Manoel Gomes da Silva, ${ }^{* *}$ \\ Manoel Adrião Gomes Filho, ${ }^{* * *}$ Airton Alencar de Araújo, ${ }^{* *}$ Davide Rondina**
}

\begin{abstract}
Resumo
O objetivo do presente estudo foi avaliar os efeitos do bagaço de caju (BC) e raspa de mandioca (RM) na alimentação sobre a produção de embriões in vivo e expressão de diferentes genes em cabras. Três dietas foram oferecidas a 28 cabras em quantidade para satisfazer 1,5 vezes as exigências de manutenção. A dieta controle foi composta por feno de tifton e concentrado (milho $80 \%$, farelo de soja $15 \%$, minerais $5 \%$ ). Nos tratamentos, o farelo de soja foi substituído parcialmente pelo bagaço de caju ou raspa de mandioca no concentrado. Após o tratamento de superovulação, os embriões foram recuperados e classificados de acordo com as normas da IETS. A expressão relativa de RNAm para IGF-IR, IGF-II, GLUT-I and HSP-70.1 em embriões caprinos foi determinada pela RT-PCR semi-quantitativa. Não houve diferença entre dietas $(p>0,05)$ na taxa de ovulação, resposta superovulatória, recuperação embrionária e taxa de fertilidade. O número de embriões não diferiu entre as dietas ( $p>0,05)$, porém no grupo BC e RM houve um incremento de mórulas $(p<0,05)$. A expressão gênica diferiu apenas para o gene HSP 70.1 no grupo RM, não havendo diferenças na expressão dos genes IGF-IR, IGF-II e GLUT-I ( $p>0,05)$. A utilização do BC e da RM foram eficientes na produção de embriões in vivo e apenas a raspa de mandioca afetou a expressão do gene HSP 70.1, relacionado com o estresse embrionário.
\end{abstract}

Palavras-chave: embrião, caprino, ovulação, produção in vivo de embriões.

\begin{abstract}
The objective of this work was to evaluate the effect of the cashew bagasse (BC) and cassava scrapes (RM) on embryos in vivo production and gene expression in goats. Three diets were offered to 28 goats in amount to satisfy 1.5 times the maintenance requirements. The control diet was composed by tifton grass hay and concentrate ( $80 \%$ corn, $15 \%$ soybean meal, $5 \%$ minerals). In the treatments, soybean meal was partially replaced by cashew bagasse or cassava root scrapings in the concentrate. After superovulation treatment, the embryos were recovered and classified according to IETS statements. The relative mRNA expression for IGF-IR, IGF-II, GLUT-I and HSP-70.1 in goat embryos were determined by semiquantitative RT-PCR. Diets did not affect ( $p>0.05$ ) the ovulation rate, superovulation response, embryo recovery and fertility rate. The number of viable embryos was similar ( $p>0.05$ ). Diets with BC and RM showed an increment of morulae stage $(p<0.05)$. Gene expression differed for HSP 70.1 gene in RM group, whereas no difference was detected for IGF-IR, IGF-II and GLUT-I expression ( $p>0.05)$. The use of the BC and the RM were efficient in the production of in vivo embryos and only cassava scrapes affected the expression of the gene related to embryo stress.
\end{abstract}

Keywords: embryo, caprine, ovulation, embryo production in vivo.

\section{Introdução}

Na espécie caprina, assim como em outros ruminantes, a nutrição influencia diretamente a fertilidade através do fornecimento de nutrientes específicos requeridos para os processos de desenvolvimento oocitário, ovulação, fertilização e sobrevivência embrionária (Boland et al., 2001). Recentemente, foi demonstrado que o consumo e o tipo de dieta podem alterar a expressão de genes envolvidos no processo de desenvolvimento embrionário inicial (Pisani et al., 2008). Neste panorama, estudos sobre a substituição ou inclusão de subprodutos da agroindústria têm-se destacado no âmbito da nutrição animal como opção alimentar, principalmente, quando utilizados em dietas balanceadas.

\footnotetext{
* Recebido em 5 de fevereiro de 2013 e aceito em 28 de março de 2013.

** Faculdade de Veterinária, Universidade Estadual do Ceará, Av. Paranjana, 1700. Campus Itaperi, CEP: 60740-000, Fortaleza, CE, Brasil.

*** Universidade Federal Rural de Pernambuco, Rua Dom Manoel de Medeiros, s/n. Dois Irmãos, CEP: 52171-900, Recife, PE, Brasil.

Autor para correspondência: Davide Rondina. E-mail: davide.rondina@uece.br.
} 
O uso de subprodutos da agroindústria constitui-se um importante recurso para a alimentação dos rebanhos, principalmente durante os períodos críticos de estresse alimentar. Assim, a utilização de subprodutos da agroindústria, como alternativa para fundamentar a base alimentar de pequenos ruminantes, pode contribuir sobremaneira no controle de resíduos poluentes ao meio ambiente, diminuir custos operacionais com a alimentação desses rebanhos (Lima, 2005), bem como diminuir a pressão sobre o uso de cereais, disponibilizando-os para a população humana (Portugal, 2002).

Os subprodutos resultantes da extração do suco do pseudofruto do caju e da raspa de mandioca são abundantes e baratos, podendo ser utilizados na alimentação animal. O subproduto do caju é potencialmente rico em nutrientes. Além disso, a safra de produção dessa fruta concentra-se na região nordeste na época seca, período que se caracteriza pela baixa produção de volumoso e concentrados comerciais com preços elevados. Com relação à raspa de mandioca, os estudos têm demonstrado que esta pode ser incluída na formulação de rações para animais domésticos, em substituição parcial ou total dos cereais, devido ao seu valor energético e palatabilidade (Amaral et al., 2007).

Diante do exposto, novas pesquisas devem ser desenvolvidas com o objetivo de determinar opções de utilização alimentar, propiciando um desempenho reprodutivo adequado, reduzindo o custo de alimentação e resultando consequentemente em maior lucratividade. Assim, este trabalho apresenta como objetivo verificar os efeitos da utilização de bagaço de caju e da raspa de mandioca na alimentação de cabras sobre a produção de embriões in vivo, bem como na expressão dos genes IGF-IR, IGF-II, GLUT-I e HSP 70.1 em embriões caprinos.

\section{Material e métodos}

O presente estudo foi aprovado pelo Comitê de Ética em Experimentação Animal da Universidade Estadual do Ceará ( $\mathrm{n}^{\circ}$ 09110257-0). O experimento foi conduzido durante o período de setembro a novembro. Vinte e oito cabras mestiças adultas homogêneas em peso $(30,5 \pm 1,2 \mathrm{~kg})$ e condição de escore corporal $(2,7 \pm 0,3)$ foram alocadas em três tratamentos distintos, onde receberam dietas em quantidade para satisfazer 1,5 vezes as exigências nutricionais de cabras em manutenção (NRC, 2007). As dietas foram fornecidas durante 32 dias, iniciando 15 dias antes do acasalamento até a colheita dos embriões, segundo a seguinte formulação: grupo controle (controle, $n=8$ ): feno de tifton e concentrado (milho $80 \%$, farelo de soja $15 \%$, minerais $5 \%$ ); grupo bagaço de caju (BC, $n=10)$ : feno de tifton e concentrado (bagaço de caju desidratado $50 \%$, milho $38 \%$, farelo de soja $7 \%$, minerais $5 \%$ ); e grupo raspa de mandioca (RM, $n=10$ ): feno de tifton e concentrado (raspa de mandioca $50 \%$, milho $38 \%$, farelo de soja $7 \%$, minerais $5 \%$ ). Os animais experimentais foram mantidos em baias coletivas, recebendo sal mineral e água ad libitum.

Os animais foram sincronizados utilizando esponjas vaginais impregnadas de $60 \mathrm{mg}$ de acetato de medroxiprogesterona (Progespon ${ }^{\circledR}$, Syntex, Buenos Aires, Argentina) por um período de 10 dias e pela aplicação de $50 \mu$ de PGF2a (Prolise ${ }^{\circledR}$, Arsa, Buenos Aires, Argentina). Para a superovulação administrou-se um total de $200 \mathrm{mg}$ de pFSH (Folltropin ${ }^{\circledR}$; Vetrepharm, Belle Ville, Canadá) IM, a cada 12 horas (40/40,40/40, 20/20mg) durante os dias 8,9 e 10. No dia 10 a esponja foi removida e 36 horas após a retirada da esponja, foram administradas $100 \mathrm{mg}$ de $\mathrm{GnRH}$
(Gestran-plus ${ }^{\circledR}$, Arsa, Buenos Aires, Argentina). Após a retirada da esponja, as fêmeas foram mantidas com machos de fertilidade comprovada por um período de 72 horas. Todas as fêmeas com cinco ou mais corpos lúteos observados no momento da colheita dos embriões foram consideradas responsivas à superovulação. Os embriões foram recuperados sete dias após o acasalamento e classificados de acordo com a Sociedade Internacional de Transferência de embriões (STRINGFELLOW e SEIDEL, 1998). O cálculo da taxa de fertilidade foi realizado da seguinte forma: (número de estruturas fecundadas / pelo número de estruturas recuperadas) x 100 .

Para recuperação dos embriões, inicialmente os animais receberam $0,1 \mathrm{mg} / \mathrm{kg}$ de sulfato de atropina $1 \%$ por via IM (Sulfato de atropina; UCB, Jaboticabal, Brasil ), 0,1 mg/kg de cloridrato de xilazina $2 \%$ por via IM (Coopazine; Coopers, São Paulo, Brasil) e 3,3mg/kg de cloridrato de cetamina $10 \%$ por via IV (Ketamina Agener; União Química, São Paulo, Brasil). As drogas foram administradas com intervalos de 10 minutos. Em seguida, realizou-se uma incisão medioventral e o trato reprodutivo foi exposto. $O$ número de corpos lúteos foi quantificado para posterior determinação da taxa de recuperação embrionária. A recuperação dos embriões foi realizada por lavagem de cada corno uterino, utilizando um cateter inserido no infundíbulo, ligado a uma seringa contendo $40 \mathrm{ml}$ de meio de lavagem (DMPBS; Nutricell, São Paulo, Brasil). Uma cânula de plástico (Tom cat; Kendall, Mansfield, $\mathrm{OH}, \mathrm{EUA}$ ) foi inserida no início de cada corno uterino para lavagem e recuperação dos embriões em tubos de 50mL (Corning, NY, EUA). Para efeito de análise dos dados, foram utilizados animais com taxa de recuperação embrionária similar.

Os embriões provenientes de cada grupo experimental, de graus I ou II e pertencentes a um mesmo estágio de desenvolvimento foram selecionados e estocados a $-8^{\circ} \mathrm{C}$ para posterior análise da expressão gênica. Cada embrião, individualmente, foi lavado em meio DMPBS (Nutricell, São Paulo, Brasil), e congelado a $-80^{\circ} \mathrm{C}$ até o momento da extração de RNAm. Para extração foram realizados pools (10 embriões/pool), o RNA total foi isolado com a solução de tri-reagent (T-9424, Sigma, USA), de acordo com as instruções do fabricante, com pequenas modificações. A contaminação por DNA foi removida pelo tratamento com DNase (Invitrogen, São Paulo, Brasil). Em seguida, o RNA foi imediatamente utilizado para formação do DNAc. Os primers utilizados para a produção de DNAc estão representados na Tabela 1.

Para a reação da transcrição reversa (RT), foi utilizado o "kit" SuperScript III (Invitrogen, São Paulo, Brasil), cujo protocolo inicia-se pela adição em tubo estéril de $8 \mu \mathrm{L}$ da solução de RNA total tratada com DNAse, $1 \mu \mathrm{l}$ de oligonucleotídeo iniciador Oligo dt $(500 \mu \mathrm{g} / \mathrm{ml}), 1 \mu \mathrm{l}$ de dNTP Mix (10nM) e $3 \mu l$ de água estéril. Essa solução foi incubada a $65^{\circ} \mathrm{C}$ por $5 \mathrm{~min}$ e, em seguida, sofreu uma segunda incubação em gelo por 1,5 min. Após essas etapas, foram adicionados à solução $4 \mu \mathrm{l}$ de tampão "First Strand" $5 \mathrm{X}, 1 \mu \mathrm{l}$ de DTT $(0,1 \mathrm{M})$ e $1 \mu \mathrm{l}$ de "RNAse OUT Inhibitor" (40unidades/ $\mu \mathrm{l}$ ). Na sequência, foi acrescido $1 \mu \mathrm{l}(200 \mathrm{U}) \mathrm{de}$ SuperScript III (transcriptase reversa) e se iniciou a incubação, primeiramente a $50^{\circ} \mathrm{C}$ por $50 \mathrm{~min}$, depois a $70{ }^{\circ} \mathrm{C}$ por $15 \mathrm{~min}$ e, finalmente, em gelo por $2 \mathrm{~min}$. As amostras foram mantidas a $-20^{\circ} \mathrm{C}$ para utilização posterior no PCR. A PCR foi realizada em $20 \mu$ contendo 1-2 $\mu$ l de DNAc (equivalente a 0,75 - 1,5 embriões), 2 IU de DNA polymerase Taq Platinum (Invitrogen, USA), $0.5 \mathrm{mM}$ de cada primer específico, $200 \mathrm{mM}$ de cada dNTP, 
Tabela 1: Detalhes dos primers utilizados para RT-PCR

\begin{tabular}{|c|c|c|c|c|}
\hline Gene & Sequência dos primers & $\begin{array}{l}\text { Temp. anelamento } \\
\left({ }^{\circ} \mathrm{C}\right)\end{array}$ & $\begin{array}{l}N^{\circ} \text { ciclo } \\
\text { PCR }\end{array}$ & $\begin{array}{l}\mathrm{N}^{\circ} \text { acesso banco } \\
\text { de genes }\end{array}$ \\
\hline GAPDH & $\begin{array}{l}\text { 5' CCCATCACCATCTTCCAGG } \\
\text { 3' AGTGAGCTTCCCGTTCAGC }\end{array}$ & 60 & 36 & 281181 \\
\hline IGF-IR & $\begin{array}{l}\text { 5' GCAGATGGCATGGCATACCT } \\
\text { 3' ATCTTCGGCCACCATGCA }\end{array}$ & 60 & 36 & X54980 \\
\hline IGF-II & $\begin{array}{l}\text { 5' CTCTGCAGCCTGCGTTGAA } \\
\text { 3' GTCACGTTTGATGGCTTCCA }\end{array}$ & 56 & 36 & L22092 \\
\hline GLUT-I & $\begin{array}{l}\text { 5' CTGTCCTGGGTCGCTTCA } \\
\text { 3' GGATACCTCCCCCACGTACA }\end{array}$ & 57 & 36 & M60448 \\
\hline HSP 70.1 & $\begin{array}{l}\text { 5' ATGACCGCCCTGATCAAGC } \\
\text { 3' CCTCGTACACCTGGATCAGCA }\end{array}$ & 57 & 36 & NM174068 \\
\hline
\end{tabular}

Em estudos anteriores com pequenos ruminantes foi demonstrado que o tipo de dieta (Rondina et al., 2005) ou a utilização de alimentos específicos (Muñoz-Gutiérrez et al., 2004) pode exercer uma ação significativa sobre a população folicular e a taxa de ovulação. Além disso, o número de folículos responsivos às gonadotrofinas no início do tratamento hormonal é um dos principais fatores que controla a resposta superovulatória. No entanto, os resultados do presente experimento demonstraram que a utilização de BC ou RM não alterou a resposta superovulatória.
$2.0 \mathrm{mM}$ de $\mathrm{MgCl}$, e Tampão PCR 1X. O programa de PCR utilizado inicial foi de $91^{\circ} \mathrm{C}$ por 4 min, seguido de 36 ciclos de $94^{\circ} \mathrm{C}$ por $1 \mathrm{mim}, 57^{\circ} \mathrm{C}$ por $1 \mathrm{~min}, \mathrm{e} 72^{\circ} \mathrm{C}$ por $1 \mathrm{~min}$. A incubação final foi realizada a $72^{\circ} \mathrm{C}$ por $5 \mathrm{~min}$. Como controle negativo, as reações foram realizadas sem a presença da transcriptase reversa durante a formação do DNAc e como controle positivo, utilizou-se o gene GAPDH. Após as amplificações, foi realizada eletroforese em gel de agarose a $1,5 \%$ corados com Blue green e fotografados em iluminação UV. A expressão gênica foi quantificada por densitometria utilizando o software ImageJ (Image J, National Institutes of Health, Millersville, USA).

As diferenças entre médias nos parâmetros de produção embrionária e expressão gênica foram analisadas pelo teste de Mann-Whitney por grupos independentes utilizando o programa software Statistica (StatSoft Inc., Tulsa, OK, EUA). Os dados da expressão gênica foram apresentados como média de, no mínimo, três pools de embriões.

\section{Resultados e discussão}

Todos os animais submetidos ao tratamento superovulatório apresentaram estro (28/28) e a taxa de recuperação embrionária foi superior em relação a outros estudos que utilizaram o mesmo método cirúrgico de colheita (Blanco et al., 2003). Não se observaram diferenças significativas entre os grupos alimentares para os parâmetros taxa de ovulação, resposta superovulatória, taxa de recuperação embrionária e fertilidade (Tabela 2).

Tabela 2: Resposta reprodutiva de cabras alimentadas com bagaço de caju (BC) ou raspa de mandioca (RM) após tratamento superovulatório. Valores da taxa de ovulação expressos em médias \pm E.P.M

\begin{tabular}{lccccc}
\hline \multirow{2}{*}{ Parâmetros } & & \multicolumn{3}{c}{ Grupos } & Total \\
\cline { 3 - 5 } & & Controle & BC & RM & \\
\cline { 3 - 5 } \cline { 3 - 5 } Taxa de ovulação & & $11,9 \pm 1,6$ & $11,9 \pm 1,9$ & $12,3 \pm 2,0$ & $12,0 \pm 1,0$ \\
Resposta superovulatória (\%) & & 100,0 & 90,0 & 90,0 & $92,8(26 / 28)$ \\
Recuperação embrionária (\%) & & 82,0 & 87,6 & 78,9 & $83,0(213 / 257)$ \\
Taxa de fertilidade (\%) & & 100,0 & 99,2 & 100,0 & $99,7(213 / 214)$ \\
\hline
\end{tabular}

O conteúdo proteico e energético da dieta, assim como outros nutrientes, é de suma importância no desenvolvimento do embrião. Dietas não balanceadas fornecidas no período precedente à fecundação influenciam negativamente a qualidade do oócito e o desenvolvimento embrionário (Papadopoulos et al., 2001; Lozano et al., 2003). Em ovinos, Pisani et al. (2008) demonstraram que a disponibilidade de nutrientes no período pré-acasalamento pode alterar a expressão de genes do oócito envolvidos no sucessivo desenvolvimento embrio-nário. Paralelamente, em outros estudos, foi relatada uma redução na taxa de oócitos clivados em ovelhas alimentadas com dietas, contendo baixa ou elevada dispo-nibilidade de energia (Borowczyk et al., 2006).

No que se refere aos parâmetros de qualidade embrionária, os grupos alimentados com subprodutos registraram um número de embriões de grau I, II e III similar $(P>0,05)$ ao grupo controle (Tabela 3). Entretanto, somente em cabras suplementadas com bagaço de caju a relação entre embriões transferíveis e degenerados apresentou diferença $(P<0,05)$. Ao avaliar 0 número médio de embriões em estágio de mórulas e blastocistos por doadora, não foram encontradas diferenças entre os grupos alimentares $(P>0,05)$. Contudo, a relação entre os dois estágios embrionários diferiu nos grupos BC e RM, onde se observou uma maior $(P<0,05)$ concentração de mórulas (Tabela 3).

Em ruminantes, a literatura relativa ao uso do bagaço de caju e da raspa de mandioca é essencialmente direcionada a resposta produtiva, enquanto os estudos específicos sobre os aspectos reprodutivos ainda são escassos. Entretanto, pesquisadores têm relatado resultados positivos utilizando diferentes subprodutos em dietas balanceadas na recuperação de oócitos em ovelhas (Grazul-Bilska et al., 2006), ou na produção e qualidade embrionária em novilhas de corte (Yaakub et al., 1999; Wrenzycki, 2005).

A expressão de genes em embriões é alterada por diferentes fatores, incluindo o tipo de dieta que pode influenciar o potencial de 
Tabela 3: Número de embriões/doadora de acordo com a classificação IETS e o estádio de desenvolvimento embrionário. Valores expressos em médias \pm E.P.M.

\begin{tabular}{|c|c|c|c|}
\hline \multirow{2}{*}{ Parâmetros } & \multicolumn{3}{|c|}{ Grupos } \\
\hline & Controle & BC & RM \\
\hline \multicolumn{4}{|l|}{ Classificação IETS } \\
\hline Embriões grau I, II e III & $7,8 \pm 0,9^{a}$ & $11,0 \pm 1,5^{a}$ & $8,0 \pm 2,6^{a}$ \\
\hline Embriões degenerados & $2,1 \pm 0,7^{a}$ & $1,5 \pm 1,1^{b}$ & $2,5 \pm 1,2^{a}$ \\
\hline \multicolumn{4}{|l|}{ Estádio de Desenvolvimento } \\
\hline Mórula & $5,6 \pm 1,5^{a}$ & $7,8 \pm 1,6^{a}$ & $7,5 \pm 2,4^{a}$ \\
\hline Blastocisto & $3,0 \pm 0,9^{a}$ & $2,1 \pm 1,1^{b}$ & $0,5 \pm 0,3^{b}$ \\
\hline
\end{tabular}

$a, b$ indicam diferenças significativas dentro de cada parâmetro na mesma coluna $(p<0,05)$.

BC - Bagaço de caju desidratado; RM - Raspa de Mandioca.
De acordo com Lonergan et al. (2006), o período pré-implantação inicial representa uma janela no desenvolvimento, durante a qual a expressão gênica do embrião está predisposta a programações aberrantes. Diferentes genes são expressos durante esse período, dentre eles destacam-se o IGF-IR, IGF-II e GLUT-I. A expressão de IGF-IR e IGF-II está diretamente relacionada com a regulação do crescimento $e$ diferenciação celular, apresentando ainda, um papel mitogênico e antiapoptótico em embriões em estádios iniciais de desenvolvimento (Riley e Moley, 2006). Já a expressão de GLUT-I em embriões caprinos está relacionada com um maior requerimento de glicose, coincidindo com o momento em que ocorre a transição do embrião da tuba uterina para o útero (Thompson et al., 1996). Em um estudo prévio, Pantaleon et al. (1998) demonstraram que o requerimento de glicose pelo embrião está associado à máxima expressão de GLUT-I, sendo este gene expresso no oócito e no embrião em todas as fases de desenvolvimento. desenvolvimento embrionário e fetal (Corcoran et al., 2006; Sagirkaya et al., 2006). Entretanto, no presente estudo não foi observada diferença significativa na expressão de IGF-IR, IGF-II e GLUT-I $(P>0,05)$ em embriões caprinos provenientes dos diferentes grupos alimentares, demonstrando que o desenvolvimento embrionário não foi afetado pelo tipo dieta fornecido (Figura 1).

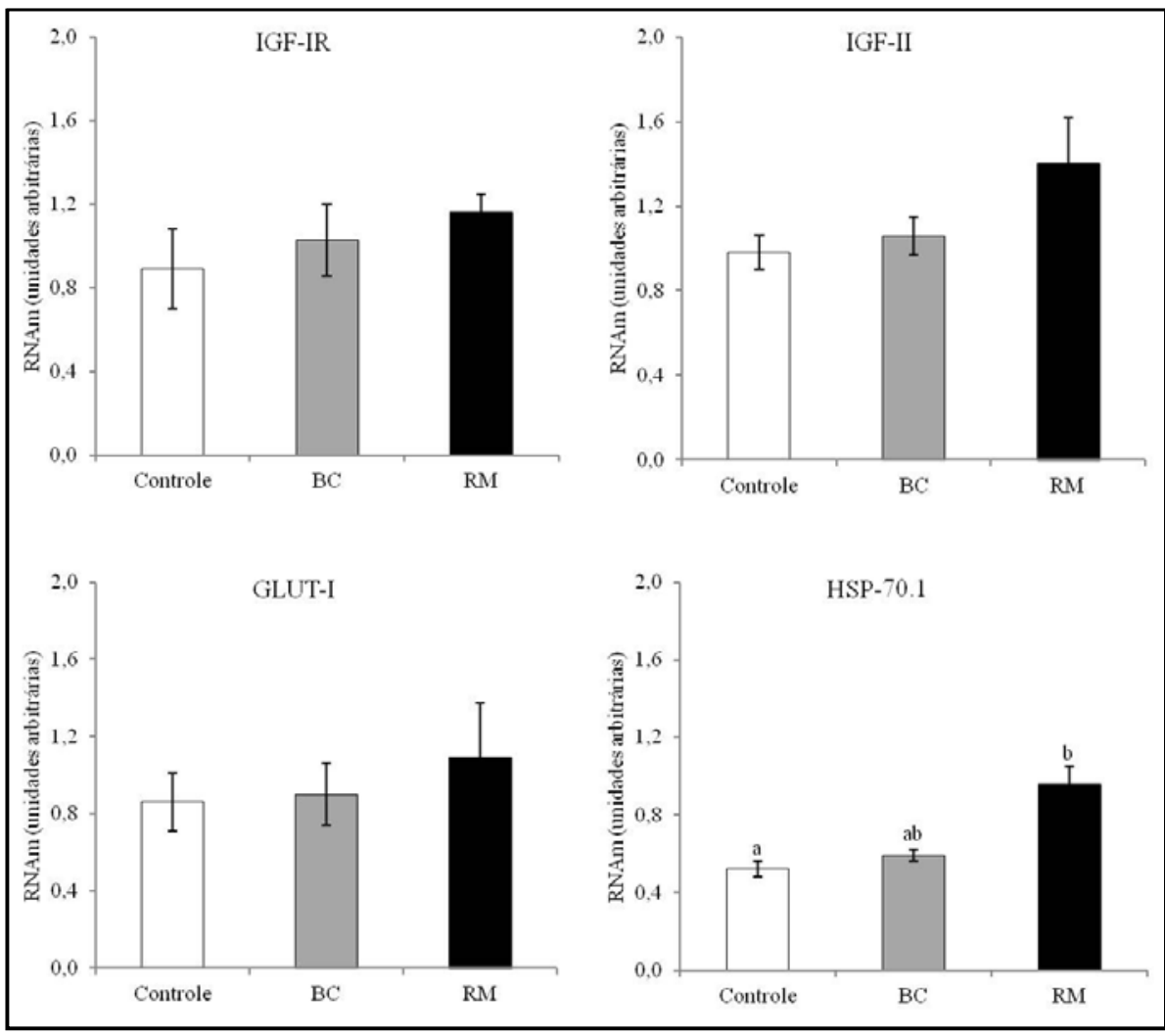

Figura1: Níveis de expressão do gene IGF-IR, IGF-II, GLUT-I e HSP-70.1 em embriões oriundos de cabras superovuladas e alimentadas com bagaço de caju desidratado (BC) e raspa de mandioca (RM). Letras diferentes entre colunas indicam diferenças estatísticas $(p<0,05)$. Valores expressos em médias \pm E.P.M.
No presente estudo, os níveis de RNAm para o gene HSP 70.1 foi superior $(P<0,05)$ no grupo RM em relação aos demais grupos alimentares (Figura 1). Estes resultados estão de acordo com estudos anteriores de Brufau et al. (1994), ao verificarem que a RM apresenta fatores antinutricionais, como os polissacarídeos não amiláceos (PNA), que provocam menor eficiência da dieta, menor ganho diário e diminuição na digestibilidade de diversos nutrientes, e ainda, é pobre em proteína, necessitando sua complementação. Diante disso, tornase evidente que a expressão gênica durante o estádio de pré-implantação pode sofrer influência epigenética, sendo particularmente sensível a fatores externos, como, por exemplo, à fonte de alimentação.

\section{Conclusões}

A utilização do bagaço de caju desidratado ou a raspa de mandioca como substitutos parciais de cereais proporciona uma produção embrionária eficiente e compatível com as formas convencionais de alimentação. No entanto, a expressão de HSP 70.1, gene relacionado com o estresse embrionário, foi alterada em embriões oriundos de cabras alimentadas com raspa de mandioca. Conjuntamente, os resultados deste estudo demonstram que a raspa de mandioca apresenta um grande potencial para ser utilizada como alimento alternativo, visando à redução de custos com a suplementação animal. No entanto, sugerimos que mais pesquisas sejam desenvolvidas a fim de validar seu uso antes que seja incorporada na alimentação de ruminantes. 


\section{Agradecimentos}

Fonte de financiamento CNPq (Proc. N. 476055/2007-5) e Renorbio (Rede Nordeste de Biotecnologia). Os autores agradecem as equipes técnicas das fazendas Campo da Semente, pelo suporte técnico e auxílio no manejo dos animais.

\section{Referências}

AMARAL, L.; JAIGOBIND, A.G.A.; JAISINGH, S. Dossiê Técnico. Processamento da mandioca. Instituto de Tecnologia do Paraná. Serviço Brasileiro de Resposta Técnica - SBRT, 2007.

BARIL, G.; BREBION, P.; CHESNE, P. Manual de Formación Práctica para el Trasplante de Embriones en Ovejas y Cabras. FAO, Roma: 182p, 1995.

BLANCO, M.R.; SIMONETI, L.; RIVERA, O.E. Embryo production and progesterone profiles in ewes superovulated with different hormonal treatments. Small Ruminant Research, v. 47, p.183-191, 2003.

BOLAND, M.P.; LONERGAN, P.; O'CALLAGHAN D. Effect of nutrition on endocrine parameters, ovarian physiology, and oocyte and embryo development. Theriogenology, v. 55, p.1323-1340, 2001.

BOROWCZYK, E.; CATON, J.S.; REDMER, D.A.; BILSKI, J.J.; WEIGL, R.M.; VONNAHME, K.A.; BOROWICZ, P.P.; KIRSCH, J.D.; KRAFT, K.C.; REYNOLDS, L.P.; GRAZUL-BILSKA, A.T. Effects of plane of nutrition on in vitro fertilization and early embryonic development in sheep. Journal of Animal Science, v. 84, p. 15931599, 2006.

BRUFAU, J.; PÉREZ-VENDRELL, A.M.; FRANCESCH, M. Papel de la fibra en la alimentación avícola. In: SIMPÓSIO DE AVICULTURA, 31., 1994. Anais... Pamplona: Sección Española de la Asociación Mundial de Avicultura Científica, 1994. p. 125-130.

CORCORAN, D.; FAIR, T.; PARK, S.; RIZOS, D.; PATEL, O.V.; SMITH, G.W.; COUSSENS, PM.; IRELAND, J.J.; BOLAND, M.P.; EVANS, AC.; LONERGAN, P. Suppressed expression of genes involved in transcription and translation in vitro compared with in vivo cultured bovine embryos. Society for Reproduction and Fertility, v. 131, p. 1741-7899, 2006.

GRAZUL-BILSKA, A.T.; PANT, D.; LUTHER, J.S. Pregnancy rates and gravid uterine parameters in single, twin and triplet pregnancies in naturally bred ewes and ewes after transfer of in vitro produced embryos. Animal Reproduction Science, v. 92, p. 268-283, 2006.

LIMA, M.L.M. Uso de subprodutos da agroindústria na alimentação de bovinos. In: Reunião anual da Sociedade Brasileira de Zootecnia, 42., 2005, Goiânia. Anais...Goiânia: Sociedade Brasileira de Zootecnia, 2005. p.322-329.

LONERGAN, P.T.; FAIR, D.; CORCORAN, A.C.; EVANS. Effect of culture environment on gene expression and developmental characteristics in IVF-derived embryos. Theriogenology, v. 65, p. 137-152, 2006.

LOZANO, J.M.; LONERGRAN, P.; BOLAND, M.P.; O'CALLAGHAN, $D$. Influence of nutrition on the effectiveness of superovulation programmes in ewes: effect on oocyte quality and postfertilization development. Reproduction, v. 125, p. 543-553, 2003.

MUÑOZ-GUTIÉRREZ, M.; BLACHE, D.; MARTIN, G.B.; SCARAMUZZI, R.J. Ovarian follicular expression of mRNA encoding the type I insulin like growth factor receptor (IGF-IR) and insulin like growth factor binding protein 2 (IGFBP2) in anoestrous sheep after 5 days of glucose or glucosamine or supplementary feeding with lupin grain. Reproduction, v. 128, p. 1-11, 2004.
NRC, 2007. Nutrient requirements of small ruminants. National Academy of Sciences, Washington, D.C. 362 p.

PANTALEON, M.; KAYE, P.L. Glucose transporters in preimplantation development. Reviews of Reproduction, v. 3, p. 77-81, 1998.

PAPADOPOULOS, S.; LONERGAN, P.; GATH, V.; QUINN, K.M.; EVANS, A.C.; O'CALLAGHAN, D.; BOLAN, M.P. Effect of diet quantity and urea supplementation on oocyte and embryo quality in sheep. Theriogenology. v. 55, p. 1059-1069, 2001.

PISANI, L.F.; ANTONINI, S.; POCAR, P.; FERRARI, S.; BREVINI, T.A.L.; RHIND, B.S.M.; GANDOLFI, F. Effects of pre-mating nutrition on mRNA levels of developmentally relevant genes in sheep oocytes and granulosa cells. Reproduction, v. 136, p. 303312, 2008.

PORTUGAL, A.V. Sistemas de produção de alimentos de origem. Revista portuguesa ciências veterinárias, v. 97, p. 63-70, 2002.

RILEY, J.K.; MOLEY, K.H. Glucose utilization and the PI3-K pathway: mechanisms for cell survival in preimplantation embryos. Reproduction, v. 131, p. 823-835, 2006.

RONDINA, D.; FREITAS, V.J.F.; SPINACI, M.; GALEATI, G. Effect of nutrition on plasma progesterone levels, metabolic parameters and small follicles development in unstimulated goats reared under constant photoperiod regimen. Reproduction in Domestic Animal, v. 40, p. 548-552, 2005.

SAGIRKAYA, H.; MISIRLIOGLU, M.; ABDULLAH, K.; FIRST, N.L.; PARRISH, J.J.; MEMILI, E. Developmental and molecular correlates of bovine preimplantation embryos. Reproduction, v. 131, p. 895-904, 2006.

STRINGFELLOW, D.A.; SEIDEL, S.M. Manual da sociedade internacional de transferência de embriões. IETS, p. 112-113, ILLINOIS, 1998.

THOMPSON, J.G. Defining the requirements for bovine embryo culture. Theriogenology, v. 45, p. 27-40, 1996.

WRENZYCKI, C.; HERRMANN, D.; LUCAS-HAHN, A.; KORSAWE, K.; LEMME, E.; NIEMANN, H. Messenger RNA expression patterns in bovine embryos derived from in vitro procedures and their implications for development. Reproduction, Fertility and Development, v.17, p. 23-35, 2005.

YAAKUB, H.; O'CALLAGHAN, D.; BOLAND, M.P. Effect of type and quality of concentrates on superovulation and embryo yield in beef heifers. Theriogenology, v. 51, p. 1259-1266, 1999. 